\title{
Article \\ Effects of Bullying Forms on Adolescent Mental Health and Protective Factors: A Global Cross-Regional Research Based on 65 Countries
}

\author{
Xiaoou Man ${ }^{1} * \mathbb{D}$, Jiatong Liu $^{1}$ and Zengxin Xue ${ }^{2}$ \\ 1 School of Humanities and Law, Northeastern University, No. 195 Chuangxin Road, Hunnan District, \\ Shenyang 110169, China; jiatong_liu@outlook.com \\ 2 College of Economics and Management, Zhejiang Agriculture and Forestry University, No. 666 Wusu Road, \\ Lin'an District, Hangzhou 310000, China; zengxinxue@outlook.com \\ * Correspondence: manxiaoou@mail.neu.edu.cn
}

check for updates

Citation: Man, X.; Liu, J.; Xue, Z. Effects of Bullying Forms on Adolescent Mental Health and Protective Factors: A Global Cross-Regional Research Based on 65 Countries. Int. J. Environ. Res. Public Health 2022, 19, 2374. https:// doi.org/10.3390/ijerph19042374 Academic Editors: Ryan D. Burns and Wonwoo Byun

Received: 30 December 2021 Accepted: 16 February 2022 Published: 18 February 2022

Publisher's Note: MDPI stays neutral with regard to jurisdictional claims in published maps and institutional affiliations.

Copyright: () 2022 by the authors Licensee MDPI, Basel, Switzerland. This article is an open access article distributed under the terms and conditions of the Creative Commons Attribution (CC BY) license (https:/ / creativecommons.org/licenses/by/ $4.0 /)$.

\begin{abstract}
Adolescent bullying is a public health issue of great global concern. Given the serious negative effect of bullying on adolescent mental health, it is critical to seek protective factors to protect adolescent mental health. From a global cross-regional perspective, the study aims to explore the relationship between forms of bullying and adolescent mental health and the role of parental support as a protective factor. Data were drawn from adolescents aged 12-17 years in 65 countries from the Global School-based Student Health Survey between 2003 and 2015. After controlling the state-fixed effects, individual adolescent behavior, and family factors, the ordinary least squares model was used to analyze the influence of bullying frequency and forms of bullying on adolescent mental health. The results found that the prevalence of bullying in the sample of 167,286 adolescents was $32.03 \%$, with the highest prevalence of bullying in the sample countries in Africa. Verbal bullying had the highest prevalence and the most significant negative effect on adolescent mental health. The study also discussed the differences in bullying among adolescents by gender, age, and region. "Parental supervision", "parental connectedness" and "parental bonding" played a positive and protective role in the mental health of adolescents who experienced bullying.
\end{abstract}

Keywords: adolescent; forms of bullying; parental support; mental health; global research

\section{Introduction}

Bullying is intentional and repeated aggressive behavior toward another person in which there is a real or perceived power imbalance, and the victim of bullying feels vulnerable and powerless to protect themselves [1-3]. Bullying includes physical assault, verbal abuse, and neglect [4]. Globally, bullying is widespread among adolescents. In a 2018 report by UNICEF, more than one-third of students aged 13-15 worldwide said they had experienced different forms of bullying [5]; data published by the World Health Organization in 2020 showed that more than 100 million children worldwide died each year from violence, including severe domestic violence as well as bullying [6]. In a survey involving 40 developing countries, the results showed that an average of $42 \%$ of boys and $37 \%$ of girls had experienced or were experiencing bullying [7].

Evidence from several longitudinal studies on the effects of bullying suggests that experiencing bullying, especially in adolescence, can severely impair a person's physical, psychological, and social functioning, leading to risky behaviors [8], anxiety [9], depression [3,10], lower levels of academic achievement [11,12], suicidal ideation, suicidal behavior, or self-harm [13-15]. At the same time, as a deliberate, repetitive act of aggression that occurs when there is a power imbalance between the perpetrator and the victim, the perpetrator repeats the bullying against the victim, and the repetition tilts the "balance" between the perpetrator and the victim, making it difficult for the victim to escape from 
the situation $[2,4]$, thus having a lasting psychological effect on the victim [16,17]. This has a long-lasting effect on the victim's psyche. Research has shown that the frequency of bullying is one of the factors that affect adolescent mental health. Adolescents are more likely to experience more severe depression when they are bullied more frequently [4], and some victims of bullying may even become perpetrators of bullying, harming peers or others [18-20].

In recent years, some studies have also begun to further explore the effects of different forms of bullying on adolescent mental health, and found that the form of bullying is also an essential factor affecting adolescent mental health. The first was to explore what forms of bullying had a profounder effect on adolescent mental health, but most of the current studies by researchers on this issue have been conducted in individual countries or regions and have not reached uniform conclusions, e.g., Maunder et al. (2010) conducted a survey of students, teachers, and staff in four secondary schools in England, and a total of 1302 people participated in this survey, and the results found that physical bullying was the most harmful to students [21]; Chen et al. (2012) selected a middle school in Taiwan, China, and conducted two samples (605 students and 869 students) and found that relational bullying such as rumor spreading and cyberbullying were more harmful than physical and verbal bullying [22]; Thomas et al. (2016) selected 10,273 secondary school students in the first adolescent health survey conducted in 2009 in Victoria, Australia, and found that neglect had the strongest association with mental health among four forms of bullying (teased or called names, spread rumors, neglect and physical bullying) [4]. In a representative cross-sectional standardized survey conducted by Baier et al. (2018) in a federal state of Germany (10,638 students in the 9th grade), psychological cyberbullying was found to be the most important influence on the mental health of boys and girls, followed by relational bullying from peers or from teachers, and girls' mental health was associated with sexual cyberbullying. There was no significant effect between physical bullying and mental health [23].

The second was to focus on the effect of different forms of bullying on adolescent mental health under the gender group. For example, Turner et al. (2013) selected 1874 students from middle and high schools in North Carolina to explain the results of the effects of different forms of bullying (physical, verbal and cyber) on mental health (including depression and suicidal intention) and found that females had higher levels of depression after cyberbullying compared with males, and there was no significant difference in suicidal intent after either form of bullying for either males or females [24]. Shongwei et al. (2021) used the database of the 2013 Eswatini Global School-based Student Health Survey to examine gender differences in the effects of different forms of bullying on mental health in a sample of 2920 children aged 15-17 years, and found that both boys and girls felt lonely and feared re-victimization after being bullied [25]. Using data from U.S. Youth Risk Behavior Surveillance System in 2015, Kim et al. (2019) found that school bullying had a greater negative psychological effect on girls than on boys [26]. Wang et al. (2009) selected a sample of 7182 U.S. adolescents in grades 6 to 10 based on the 2005 Health Behavior in School-Aged Children Survey, and found that boys were more likely to involve physical or verbal bullying and girls were more likely to be involved in relational bullying [27]. Very few studies have focused on the effects of different forms of bullying on adolescent mental health according to age groups, and Yen et al. (2014) found that adolescents in middle school had more severe mental health problems after bullying than those in high school [28].

In addition to exploring the negative effects of bullying on adolescents, there were very few studies that analyze the role and effect of protective factors in preventing the occurrence of multiple forms of violence as positive actions to build resilience in children, in terms of protective factors [29-31]. For example, Biswas et al. (2020) used data from the Global School-based Student Health Survey to divide protective factors into parental support and peer support, and explored the effect of each on the mental health of adolescents following bullying [32]. 
Although some studies have been conducted on the effect of bullying on adolescent mental health, there are still the following research gaps: Firstly, for the global prevalence of adolescent bullying, the current studies are mostly limited to one country or a few regions [33,34], the findings are not consistent across countries, and there is a lack of crossregional comparative studies. Secondly, in addition to focusing on the effect of bullying on the mental health of adolescents as a whole and different gender groups, there are not enough studies on the effect of bullying on the mental health of different adolescent subgroups. Adolescents are at a critical stage of development and the influence of age on their behaviors is crucial, but there is a lack of research discussing the effect of different forms of bullying on mental health according to age groups. Thirdly, current research has focused more on the risk factors of adolescent bullying and not enough on protective factors $[31,35,36]$. Therefore, to address these limitations, this study attempts to analyze the frequency of bullying, the prevalence of different forms of bullying, and the effects of both on adolescent mental health in 65 countries from a cross-regional comparative perspective, and to explore the differences in the effects of different forms of bullying on adolescent mental health by gender and age groups in different regions. In addition, the study focused on parental support as a protective factor to examine the relationship between parental support and the mental health of adolescents who experienced bullying, and the mental health of adolescents who experienced different forms of bullying. The following were our hypotheses:

Hypothesis 1 (H1). Forms of bullying would be associated with adolescents' psychological well-being.

Hypothesis 2 (H2). Forms of bullying would have significantly different effects on different genders and ages.

Hypothesis 3 (H3). Parental support would play a moderating role in psychological well-being of adolescents who experienced bullying.

\section{Materials and Methods}

\subsection{Data and Sample}

Global School-based Student Health Survey (GSHS) is a World Health Organization international survey of adolescents that uses primarily standardized, self-administered questionnaires to make results comparable between countries. The core questionnaire looks at 10 domains of key factors affecting adolescent health, including tobacco use, alcohol abuse, drug use, diet, hygiene, physical activity, sexual behavior, violent behavior, and unintentional injuries, protective factors, and mental health. For the actual survey, the GSHS was approved by national governments and sponsored or organized by official agencies at the national level (usually by Ministry of Health or Education, and an institutional review board or ethical committee), using a school-class two-stage whole-group sampling method. Questionnaires were translated into the national language for student comprehension. After excluding the samples with missing data, countries covering the key variables of this study were selected, using the most recent data available for each country, and the final sample was drawn from survey data from 2003 to 2015, for a total of 167,286 samples from 65 countries, 5 regions (21,501 samples from Africa, 59,326 samples from Americas, 23,222 samples from Eastern Mediterranean, 13,301 samples from South East Asia, 49,936 samples from Western Pacific).

\subsection{Ethics Statement}

GSHS received ethics approval from each country. Written informed consent was obtained from participants or guardians prior to the survey, and privacy protections were obtained. The current study used publicly available data. 


\subsection{Measures}

\subsubsection{Dependent Variable: Mental Health}

"Mental health": Mental health was measured based on the two indicators of loneliness and anxiety in the questionnaire [37], with the questions "During the past 12 months, how often have you felt lonely/been so worried about something that you could not sleep at night?". In order to visually explain the effect of bullying on adolescent mental health, this paper recoded the responses to the above measurement questions as " 1 = always, 2 = most of the time, $3=$ sometimes, $4=$ rarely, $5=$ never". The current methods for comprehensive index measurement include subjective weighting method and objective weighting method. The subjective weighting method determines the weight based on the researcher's subjective attention to the evaluation indicators, and the objective weighting method is based on the correlation between the indicators or indicators [38]. The degree of dispersion of information determines the weight. In order to eliminate the subjective arbitrariness of determining weights, following Huang's research [39], this study chose the entropy method in the objective weighting method to determine the weights between the various indicators of the observed variable "mental health", and used the information carried by the entropy value to calculate the "mental health". According to the entropy method, the study determined the weight of each index as follows: there were N samples and $\mathrm{M}$ evaluation indexes, which were the value of the $\mathrm{j}$-th index of the $\mathrm{i}$-th sample.

Since the various indicators of sample mental health had different dimensions and orders of magnitude, the range standardized formula was used to process the indicators, and the absolute values of the indicators were converted into relative values to solve the homogeneity problem of various indicators, as shown below:

$$
Z_{i j}=\frac{x_{i j}-\min x_{j}}{\max _{j}-\min x_{j}}
$$

The formula following shows the standardized value of the $j$-th index of the $i$-th sample, the minimum and maximum value of the j-th index. In order to ensure the non-negativity of the calculation results, this study would shift the coordinates by 1 unit:

$$
\mathrm{x}_{\mathrm{ij}}^{\prime}=\mathrm{Z}_{\mathrm{ij}}+1
$$

Finally, the standardized values were used to calculate the mental health " $\mathrm{MH}$ " of adolescents in the sample:

$$
\mathrm{MH}=\sum_{\mathrm{i}=1}^{\mathrm{m}} \mathrm{w}_{\mathrm{j}} \mathrm{P}_{\mathrm{ij}}=\Sigma\left[\frac{1-\mathrm{e}_{\mathrm{j}}}{\sum_{\mathrm{i}=\mathrm{j}}^{\mathrm{m}}\left(1-\mathrm{e}_{\mathrm{j}}\right)} \times \frac{\mathrm{x}_{\mathrm{ij}}^{\prime}}{\sum_{\mathrm{i}=\mathrm{j}}^{\mathrm{n}} \mathrm{x}_{\mathrm{ij}}^{\prime}}\right]
$$

The formula above represents the entropy value of the $\mathrm{j}$-th index, $\mathrm{k}=1 / \operatorname{In}(\mathrm{n}) ; \mathrm{n}$ is the sample size, which is the weight of the j-th index of the i-th sample. Finally, the evaluation score of "mental health" was calculated as 1.02-9.89, and the higher the score, the better the mental health status.

\subsubsection{Independent Variables: Frequency and Forms of Being Bullied}

"Frequency of being bullied": "Frequency of being bullied" was measured by the question "During the past 30 days, on how many days were you bullied?" and recoded ( $1=1$ to 5 days, $2=6$ to 19 days, 3 = more than 20 days). The larger value represented the higher frequency of being bullied.

"Forms of being bullied": "Forms of being bullied" was measured by the question "During the past 30 days, how were you bullied most often?" and recoded $(1=$ physical bullying, 2 = verbal bullying, 3 = neglect). 


\subsubsection{Control Variables}

Previous studies have reported that individual factors contributing to adolescent mental health, such as age, gender [40], substance use [26,41], weight status [42] and family socioeconomic status [43]. Therefore, the study used the following variables related to mental health of adolescents in GSHS as control variables, including age, gender, physical well-being, cigarette smoking, alcohol use, proxy of family socioeconomic status, number of close friends and frequency of missing school.

"Weight status" was measured by the value of body mass index (BMI), calculated with two adolescents' indicators of height and weight, and recoded ( $1=$ underweight, 2 = normal weight, 3 = overweight) $[44,45]$. "Cigarette smoking" and "alcohol use" were measured by the questions "During the past 30 days, on how many days did you smoke cigarettes / have at least drink containing alcohol?" and recoded ( $1=$ less than 5 days, $2=6-19$ days, $3=$ more than 20 days).

According to a prior study [14], "proxy of family socioeconomic status" was measured by the question "During the past 30 days, how often did you go hungry because there was not enough food in your home?" and recoded (1 represents "low", 5 represents "high"). The larger value represented the higher family socioeconomic status.

"Number of close friends" was measured by the question "How many close friends do you have?" ( $0=0$ friends, $1=1$ friend, $2=2$ friends, $3=3$ or more friends). "Frequency of missing school" was measured by the question "During the past 30 days, on how many days did you miss classes or school without permission?" ( 1 = less than 2 days, 2 = 3-9 days, $3=$ more than 10 days).

\subsubsection{Protective Factors: Parental Supports}

Protective factors were assessed by parental supports. As critical factors of resiliency, parental supports included parental supervision, parental connectedness and parental bonding [34,35], based on the questions "how often did your parents or guardians check to see if your homework was done?", "how often did your parents or guardians understand your problems and worries?", and "how often did your parents or guardians really know what you were doing with your free time?", and assessed by frequency in the past 30 days (1 represents "never", 5 represents "always").

\subsection{Statistical Analysis}

Firstly, the study conducted descriptive statistics on the overall prevalence of maltreatment and the prevalence of different forms of maltreatment among adolescents aged 12-17 years in 65 sample countries among five regions, and to visualize the differences in the distribution of bullying across regions, a global distribution of bullying rates among adolescents in the 65 sample countries was drawn. Secondly, an ordinary least squares model was used to analyze the effects of bullying frequency and different forms of bullying on adolescent mental health. In the model estimation, state-fixed effects were controlled for in addition to the effects of the above-mentioned control variables on adolescent mental health. The study further regressed subgroups by gender and age to estimate differences in the effects of bullying exposure, bullying frequency, and forms of bullying on adolescent mental health by gender and by age (under 15, over 15) across continents, respectively. The reason for choosing 15 years as the age group cut-off was that in most countries, adolescents under 15 years are at the middle school level and those over 15 years are at the high school level, where they show more significant differences in psychological and behavioral aspects [28]. Finally, the study conducted moderation test to explore the protective factors of adolescent bullying, i.e., whether parental support could play a significant positive role in the effect of bullying on adolescent mental health. The study used Stata 15.0 to analyze the data and ArcGIS software for mapping. 


\section{Results}

\subsection{Sample Description}

The descriptive statistics of the sample are shown in Table 1 . The mean age of the sample adolescents was 14.14 years $(\mathrm{SD}=1.20)$, of which $46.74 \%$ were male $(78,187)$ and $53.26 \%$ were female $(89,099)$. In terms of bullying prevalence, $32.03 \%$ of the 167,286 overall samples of adolescents aged 12-17 years had experienced bullying in the past 30 days of the survey. Regarding the frequency of bullying, $24.68 \%$ of adolescents were bullied for less than five days, less than $10 \%$ of adolescents were bullied for more than five days.

Table 1. Descriptive statistics of the sample $(\mathrm{N}=167,286)$.

\begin{tabular}{|c|c|c|c|c|c|c|}
\hline \multirow[b]{2}{*}{ Variable } & \multicolumn{6}{|c|}{ Percentage/Mean (SD) } \\
\hline & Total & African & Americas & $\begin{array}{c}\text { Eastern } \\
\text { Mediterranean }\end{array}$ & $\begin{array}{l}\text { South East } \\
\text { Asia }\end{array}$ & $\begin{array}{l}\text { Western } \\
\text { Pacific }\end{array}$ \\
\hline \multicolumn{7}{|l|}{ Independent variable } \\
\hline Being bullied & $32.03 \%$ & $47.36 \%$ & $26.23 \%$ & $41.53 \%$ & $33.19 \%$ & $27.58 \%$ \\
\hline \multicolumn{7}{|l|}{ Frequency of being bullied } \\
\hline 1-5 days & $24.68 \%$ & $35.68 \%$ & $20.46 \%$ & $31.31 \%$ & $26.73 \%$ & $21.34 \%$ \\
\hline 6-19 days & $4.06 \%$ & $6.60 \%$ & $3.10 \%$ & $5.52 \%$ & $3.97 \%$ & $3.44 \%$ \\
\hline$>20$ days & $3.28 \%$ & $5.08 \%$ & $2.67 \%$ & $4.70 \%$ & $2.50 \%$ & $2.79 \%$ \\
\hline \multicolumn{7}{|l|}{ Form of being bullied } \\
\hline Physical & $24.02 \%$ & $28.98 \%$ & $18.84 \%$ & $24.71 \%$ & $25.66 \%$ & $24.26 \%$ \\
\hline Verbal & $66.36 \%$ & $61.75 \%$ & $71.09 \%$ & $68.19 \%$ & $63.24 \%$ & $65.12 \%$ \\
\hline Neglect & $9.62 \%$ & $9.26 \%$ & $10.07 \%$ & $7.11 \%$ & $11.10 \%$ & $10.61 \%$ \\
\hline \multicolumn{7}{|l|}{ Dependent variable } \\
\hline Psychological well-being & $5.79(1.82)$ & $5.47(1.92)$ & $5.89(1.81)$ & $5.69(2.00)$ & $5.97(1.78)$ & $5.81(1.70)$ \\
\hline \multicolumn{7}{|l|}{ Control variable } \\
\hline Age & $14.14(1.20)$ & $14.45(1.29)$ & $13.89(0.99)$ & $13.85(0.95)$ & $14.05(1.18)$ & $14.45(1.37)$ \\
\hline \multicolumn{7}{|l|}{ Gender } \\
\hline Male & $46.74 \%$ & $45.81 \%$ & $46.77 \%$ & $47.10 \%$ & $45.20 \%$ & $47.34 \%$ \\
\hline Female & $53.26 \%$ & $54.19 \%$ & $53.23 \%$ & $52.90 \%$ & $54.80 \%$ & $52.66 \%$ \\
\hline \multicolumn{7}{|l|}{ Weight status } \\
\hline Underweight & $26.63 \%$ & $20.66 \%$ & $17.29 \%$ & $27.45 \%$ & $48.43 \%$ & $34.12 \%$ \\
\hline Normal weight & $63.69 \%$ & $75.31 \%$ & $73.17 \%$ & $62.76 \%$ & $47.86 \%$ & $52.09 \%$ \\
\hline Overweight & $9.67 \%$ & $4.03 \%$ & $9.55 \%$ & $9.80 \%$ & $3.71 \%$ & $13.79 \%$ \\
\hline \multicolumn{7}{|l|}{ Cigarettes smoking } \\
\hline$<5$ days & $96.11 \%$ & $97.72 \%$ & $95.98 \%$ & $95.96 \%$ & $97.58 \%$ & $95.24 \%$ \\
\hline 6-19 days & $1.92 \%$ & $1.13 \%$ & $2.22 \%$ & $2.01 \%$ & $1.17 \%$ & $2.05 \%$ \\
\hline$>20$ days & $1.98 \%$ & $1.14 \%$ & $1.80 \%$ & $2.03 \%$ & $1.26 \%$ & $2.71 \%$ \\
\hline \multicolumn{7}{|l|}{ Alcohol use } \\
\hline$<5$ days & $95.97 \%$ & $96.73 \%$ & $91.84 \%$ & $99.58 \%$ & $98.65 \%$ & $98.17 \%$ \\
\hline 6-19 days & $2.91 \%$ & $2.08 \%$ & $6.11 \%$ & $0.31 \%$ & $0.90 \%$ & $1.19 \%$ \\
\hline$>20$ days & $1.12 \%$ & $1.19 \%$ & $2.05 \%$ & $0.12 \%$ & $0.44 \%$ & $0.63 \%$ \\
\hline Socioeconomic status & $4.20(1.01)$ & $3.89(1.09)$ & $4.39(0.93)$ & $4.36(1.03)$ & $4.18(1.05)$ & $4.04(1.01)$ \\
\hline Close friendship & $2.41(0.92)$ & $1.91(1.04)$ & $2.45(0.91)$ & $2.39(0.91)$ & $2.53(0.83)$ & $2.56(0.84)$ \\
\hline \multicolumn{7}{|l|}{ Frequency of missing school } \\
\hline$<2$ days & $91.58 \%$ & $90.04 \%$ & $90.93 \%$ & $90.64 \%$ & $94.77 \%$ & $92.52 \%$ \\
\hline 3-9 days & $6.62 \%$ & $7.82 \%$ & $6.89 \%$ & $7.48 \%$ & $4.04 \%$ & $6.13 \%$ \\
\hline$>10$ days & $1.80 \%$ & $2.14 \%$ & $2.18 \%$ & $1.87 \%$ & $1.20 \%$ & $1.35 \%$ \\
\hline Parental supervision & $2.94(1.49)$ & $3.14(1.51)$ & $2.97(1.51)$ & $3.37(1.56)$ & $3.15(1.42)$ & $2.57(1.36)$ \\
\hline Parental connectedness & $3.00(1.46)$ & $3.11(1.44)$ & $3.16(1.48)$ & $3.16(1.48)$ & $2.98(1.44)$ & $2.81(1.37)$ \\
\hline Parental bonding & $3.19(1.44)$ & $3.06(1.43)$ & $3.34(1.46)$ & $3.34(1.50)$ & $3.35(1.39)$ & $3.17(1.36)$ \\
\hline
\end{tabular}

In terms of mental health, the mean of mental health of adolescents in the sample countries was 5.79 (SD = 1.82), which was in the middle to upper level. Among different regions, the mental health level of adolescents in South East Asia was the highest $(\mathrm{M}=5.97, \mathrm{SD}=1.78)$, and African adolescents' mental health level was the lowest $(\mathrm{M}=5.47$, $\mathrm{SD}=1.92)$. 
In terms of parental support, the mean values of "parental supervision", "parental connectedness", and "parental bonding" for the overall sample of adolescents were 2.94 (SD = 1.49), $3.00(\mathrm{SD}=1.46)$, and 3.19 (SD = 1.44), respectively. The mean values of "parental supervision" ranged from "rarely" to "sometimes", and the mean values of "parental connectedness" and "parental bonding" ranged from "sometimes" to "most of the time".

\subsection{Prevalence and Forms of Bullying across the Regions}

Table 1 shows the prevalence of different forms of bullying in the six regions. Overall, verbal bullying had the highest prevalence (66.36\%), followed by physical bullying (24.02\%), and the neglect had the lowest prevalence (9.62\%). Across regions, physical bullying was highest in Africa (28.98\%) and lowest in the Americas (18.84\%); verbal bullying was the opposite of physical bullying, highest in the Americas (71.09\%) and lowest in Africa $(61.75 \%)$; neglect was highest in South East Asia $(11.10 \%)$ and lowest in Eastern Mediterranean (7.11\%).

Table 2 and Figure 1 show specifically the prevalence of bullying and different forms of bullying in each sample country. In terms of bullying prevalence, the African region had the highest prevalence of adolescent bullying at $47.36 \%$, followed by Eastern Mediterranean (41.53\%), South East Asia (33.19\%), Western Pacific (27.58\%), and the Americas (26.23\%). In terms of sample countries, 5 of the 12 sample countries in Africa had more than half of the bullying prevalence, namely, Botswana (52.20\%), Ghana (56.72\%), Kenya (54.35\%), Zambia $(61.58 \%)$, and Zimbabwe (59.15\%). In Americas, the prevalence of bullying was ranging from $47.14 \%$ in Peru to $12.50 \%$ in Barbados. The Eastern Mediterranean region had the highest bullying rate in the Occupied Palestinian Territory with over half $(52.27 \%)$ and the lowest bullying rate in Iraq (27.45\%). South East Asia also had more than half of adolescents in Indonesia (50.14\%) as its highest bullying rate, and the lowest adolescent bullying rate was in Myanmar (19.51\%). Samoa, in the Western Pacific region, had the highest prevalence of bullying among all countries in the sample, at $72.40 \%$, while Malaysia $(16.99 \%)$ had the lowest prevalence of bullying among adolescents in the Western Pacific region.

Table 2. Prevalence and forms of bullying across regions $(\mathrm{N}=167,286)$.

\begin{tabular}{|c|c|c|c|c|c|}
\hline Region & $\begin{array}{c}\text { Being Bullied } \\
(\%)\end{array}$ & $\begin{array}{c}\text { Physical } \\
(\%)\end{array}$ & $\begin{array}{c}\text { Verbal } \\
(\%)\end{array}$ & $\begin{array}{l}\text { Neglect } \\
(\%)\end{array}$ & $\begin{array}{c}\text { Total Sample } \\
\text { (n) }\end{array}$ \\
\hline Total & 32.03 & 4.50 & 12.43 & 1.80 & 167,286 \\
\hline African & 47.36 & 9.65 & 20.56 & 3.08 & 21501 \\
\hline Benin & 42.46 & 6.28 & 19.96 & 0.75 & 1067 \\
\hline Botswana & 52.20 & 11.64 & 23.90 & 3.53 & 1134 \\
\hline Ghana & 56.72 & 12.79 & 20.15 & 2.31 & 2119 \\
\hline Kenya & 54.35 & 13.56 & 26.94 & 5.47 & 2138 \\
\hline Mauritania & 47.46 & 6.30 & 15.50 & 2.10 & 1142 \\
\hline Namibia & 45.59 & 8.27 & 17.19 & 1.80 & 2937 \\
\hline Seychelles & 47.26 & 3.56 & 17.46 & 1.37 & 1094 \\
\hline Swaziland & 31.28 & 5.91 & 11.66 & 0.92 & 2487 \\
\hline Uganda & 43.09 & 11.66 & 20.52 & 2.54 & 1613 \\
\hline Tanzania & 25.74 & 6.78 & 9.48 & 2.13 & 1593 \\
\hline Zambia & 61.58 & 13.07 & 34.52 & 4.93 & 872 \\
\hline Zimbabwe & 59.15 & 12.22 & 29.89 & 6.54 & 3305 \\
\hline Americas & 26.23 & 2.77 & 10.44 & 1.48 & 59326 \\
\hline Antigua and Barbuda & 26.87 & 3.55 & 12.75 & 0.55 & 1098 \\
\hline Argentina & 25.07 & 1.79 & 9.97 & 1.32 & 19559 \\
\hline Bahamas & 21.74 & 2.42 & 10.03 & 1.09 & 1196 \\
\hline Barbados & 12.50 & 2.11 & 4.94 & 0.36 & 1376 \\
\hline Belize & 30.29 & 4.05 & 12.07 & 1.40 & 1433 \\
\hline Bolivia & 30.51 & 3.07 & 10.08 & 1.63 & 2511 \\
\hline British Virgin Is. & 18.06 & 1.80 & 7.91 & 0.63 & 1113 \\
\hline Cayman Is. & 26.51 & 5.26 & 11.50 & 1.36 & 1026 \\
\hline
\end{tabular}


Table 2. Cont.

\begin{tabular}{|c|c|c|c|c|c|}
\hline Region & $\begin{array}{l}\text { Being Bullied } \\
(\%)\end{array}$ & $\begin{array}{l}\text { Physical } \\
(\%)\end{array}$ & $\begin{array}{l}\text { Verbal } \\
(\%)\end{array}$ & $\begin{array}{l}\text { Neglect } \\
(\%)\end{array}$ & $\begin{array}{l}\text { Total Sample } \\
\text { (n) }\end{array}$ \\
\hline Costa Rica & 19.34 & 1.34 & 8.68 & 1.39 & 2166 \\
\hline Curacao & 26.59 & 0.73 & 12.90 & 1.17 & 2046 \\
\hline El Salvador & 25.30 & 3.43 & 8.85 & 1.99 & 3965 \\
\hline Ecuador & 22.50 & 1.39 & 8.76 & 1.46 & 1507 \\
\hline Grenada & 27.77 & 3.76 & 12.65 & 1.28 & 1091 \\
\hline Guyana & 38.32 & 4.78 & 13.56 & 2.19 & 1777 \\
\hline Honduras & 31.00 & 1.89 & 12.15 & 2.69 & 1374 \\
\hline Jamaica & 36.91 & 5.37 & 14.36 & 1.46 & 1024 \\
\hline Montserrat & 28.77 & 5.48 & 12.33 & 10.96 & 146 \\
\hline Peru & 47.14 & 4.24 & 17.83 & 4.51 & 2238 \\
\hline St. Kitts and Nevis & 22.07 & 4.16 & 8.77 & 0.89 & 1346 \\
\hline St. Lucia & 25.20 & 2.87 & 10.76 & 1.43 & 976 \\
\hline $\begin{array}{l}\text { St. Vincent and the } \\
\text { Grenadines }\end{array}$ & 28.48 & 5.43 & 11.07 & 1.43 & 976 \\
\hline Suriname & 26.26 & 0.91 & 7.55 & 0.30 & 994 \\
\hline Trinidad and Tobago & 15.77 & 2.90 & 6.30 & 0.50 & 2207 \\
\hline Uruguay & 18.98 & 0.74 & 9.60 & 1.26 & 2689 \\
\hline Venezuela & 32.36 & 6.98 & 12.40 & 1.81 & 3483 \\
\hline Eastern Mediterranean & 41.53 & 5.42 & 14.95 & 1.56 & 23222 \\
\hline Bahrain & 40.06 & 10.92 & 20.17 & 1.26 & 714 \\
\hline Djibouti & 40.06 & 10.92 & 20.17 & 1.26 & 714 \\
\hline Iraq & 27.45 & 6.10 & 7.12 & 0.58 & 1377 \\
\hline Jordan & 41.57 & 5.35 & 14.96 & 1.47 & 1364 \\
\hline Lebanon & 23.79 & 5.08 & 8.44 & 0.33 & 1812 \\
\hline $\begin{array}{l}\text { Occupied Palestinian } \\
\text { territory }\end{array}$ & 52.27 & 5.67 & 18.22 & 1.96 & 11614 \\
\hline Qatar & 37.40 & 4.28 & 13.58 & 1.67 & 1377 \\
\hline Tunisia & 30.28 & 3.79 & 11.69 & 1.58 & 2087 \\
\hline United Arab Emirates & 22.10 & 2.64 & 8.41 & 1.20 & 2163 \\
\hline South East Asia & 33.19 & 4.68 & 11.53 & 2.02 & 13301 \\
\hline Indonesia & 50.14 & 4.49 & 20.20 & 4.53 & 2559 \\
\hline Maldives & 32.73 & 3.17 & 9.84 & 1.58 & 1830 \\
\hline Myanmar & 19.51 & 4.77 & 7.84 & 1.66 & 1927 \\
\hline Sri Lanka & 36.00 & 4.26 & 6.96 & 2.47 & 2228 \\
\hline Thailand & 28.23 & 6.42 & 12.94 & 0.74 & 2288 \\
\hline Timor Leste & 28.72 & 4.66 & 9.48 & 0.81 & 2469 \\
\hline Western Pacific & 27.58 & 3.86 & 10.37 & 1.69 & 49936 \\
\hline Brunei & 20.40 & 1.45 & 7.41 & 1.32 & 2417 \\
\hline China & 28.29 & 5.30 & 8.71 & 1.83 & 7780 \\
\hline Cook Is. & 27.14 & 3.95 & 9.54 & 1.32 & 608 \\
\hline Kiribati & 34.96 & 8.24 & 18.27 & 0.64 & 1396 \\
\hline Malaysia & 16.99 & 1.51 & 7.88 & 0.63 & 23476 \\
\hline Mongolia & 27.62 & 4.18 & 4.71 & 4.95 & 4885 \\
\hline Nauru & 38.72 & 10.44 & 15.15 & 0.67 & 297 \\
\hline Philippines & 48.22 & 4.29 & 15.46 & 3.70 & 3544 \\
\hline Samoa & 72.40 & 13.06 & 34.66 & 2.91 & 1685 \\
\hline Solomon Is. & 63.55 & 10.61 & 24.68 & 3.58 & 782 \\
\hline Tonga & 51.00 & 8.54 & 20.67 & 2.00 & 1698 \\
\hline Tuvalu & 29.62 & 6.87 & 7.04 & 0.65 & 611 \\
\hline Vanuatu & 65.92 & 14.93 & 21.80 & 2.11 & 757 \\
\hline
\end{tabular}

\subsection{Effects of Bullying on Psychological Well-Being of Adolescents}

After controlling for state-fixed effects, the study used OLS models to examine the effect of bullying and different forms of bullying on adolescent mental health, and the results are shown in Table 3. In Model 1, with bullying frequency as the core explanatory variable, the regression results showed that bullying frequency negatively affected ado- 
lescent mental health, with the largest negative effect on mental health for adolescents who had been bullied for more than 20 days in the past 30 days, with a 7.53 decrease in mental health $(p<0.001, \mathrm{CI}:-7.72,-7.33)$. Model 2 further estimated the effects of different forms of bullying on adolescent mental health, and the results showed that verbal bullying negatively affected adolescent mental health mostly, with a 9.64 decrease in mental health $(p<0.001, \mathrm{CI}:-9.89,-1.01)$. Physical and neglect also negatively affected adolescent mental health, with a $7.49(p<0.001, \mathrm{CI}:-7.89,-7.10)$ and a $1.21(p<0.001, \mathrm{CI}:-1.27$, $-1.15)$ decrease in mental health, respectively, which verified $\mathrm{H} 1$.
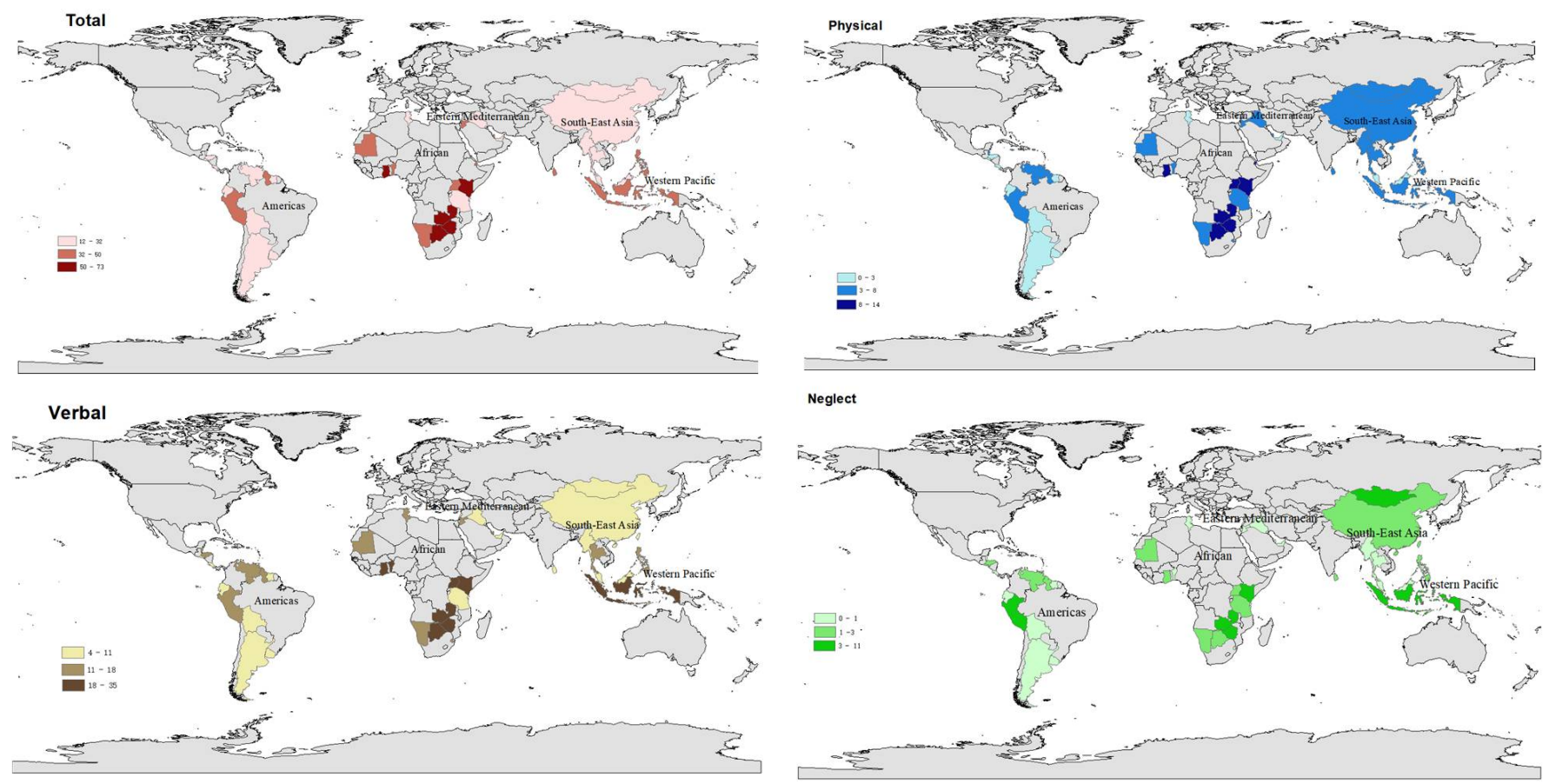

Figure 1. Prevalence of frequency of being bullied and forms of bullying in 65 countries.

Table 3. Effects of bullying on psychological well-being of adolescents $(\mathrm{N}=167,286)$.

\begin{tabular}{|c|c|c|}
\hline & Model 1 (95\% CI) & Model 2 (95\% CI) \\
\hline \multicolumn{3}{|c|}{ Frequency of being bullied } \\
\hline $1-5$ days & $-1.22^{* * *}(-1.27,-1.18)$ & \\
\hline 6-19 days & $-1.43^{* * *}(-1.47,-1.38)$ & \\
\hline$>20$ days & $-7.53^{* * *}(-7.72,-7.33)$ & \\
\hline \multicolumn{3}{|l|}{ Form of being bullied } \\
\hline Physical & & $-7.49^{* * *}(-7.89,-7.10)$ \\
\hline Verbal & & $-9.64^{* * *}(-9.89,-1.01)$ \\
\hline Neglect & & $-1.21^{* * *}(-1.27,-1.15)$ \\
\hline Age & $-1.29^{* * *}(-1.36,-1.23)$ & $-1.27^{* * *}(-1.33,-1.20)$ \\
\hline Gender (Female) & $-5.97^{* * *}(-6.13,-5.81)$ & $-5.80^{* * *}(-5.96,-5.63)$ \\
\hline \multicolumn{3}{|l|}{ Weight Status } \\
\hline Normal weight & $-1.28^{* * *}(-1.46,-1.09)$ & $-1.25^{* * *}(-1.43,-1.06)$ \\
\hline Overweight & $-7.60 * * *(-9.41,-3.42)$ & $-4.47^{* * *}(-7.48,-1.05)$ \\
\hline \multicolumn{3}{|l|}{ Cigarettes smoking } \\
\hline 6-19 days & $-3.43^{* * *}(-4.02,-2.84)$ & $-3.84^{* * *}(-4.43,-3.25)$ \\
\hline$>20$ days & $-3.64^{* * *}(-4.22,-3.05)$ & $-4.16^{* * *}(-4.75,-3.57)$ \\
\hline \multicolumn{3}{|l|}{ Alcohol use } \\
\hline 6-19 days & $-3.13^{* * *}(-3.61,-2.65)$ & $-3.23^{* * *}(-3.71,-2.75)$ \\
\hline$>20$ days & $-3.84^{* * *}(-4.61,-3.07)$ & $-4.46^{* * *}(-5.23,-3.69)$ \\
\hline
\end{tabular}


Table 3. Cont.

\begin{tabular}{|c|c|c|}
\hline & Model 1 (95\% CI) & Model $2(95 \%$ CI) \\
\hline \multicolumn{3}{|l|}{ Socioeconomic status } \\
\hline Middle-low & $-2.64^{* * *}(-3.32,-1.97)$ & $-2.47^{* * *}(-3.15,-1.80)$ \\
\hline Middle & $-2.64(-8.25,2.96)$ & $2.07(-3.55,7.68)$ \\
\hline Middle-high & $2.66^{* * *}(2.10,3.22)$ & $3.29 * * *(2.73,3.85)$ \\
\hline High & $6.15^{* * *}(5.60,6.69)$ & $6.74^{* * *}(6.20,7.28)$ \\
\hline \multicolumn{3}{|l|}{ Close friendship } \\
\hline 1 friend & $1.27^{* * *}(0.04,1.71)$ & $1.45^{* * *}(1.05,1.84)$ \\
\hline 2 friends & $1.65^{* * *}(1.27,2.02)$ & $1.89 * * *(1.52,2.27)$ \\
\hline 3 or more friends & $3.58^{* * *}(3.24,3.91)$ & $3.82 * * *(3.48,4.15)$ \\
\hline \multicolumn{3}{|c|}{ Frequency of missing school } \\
\hline 3-9 days & $-2.63^{* * *}(-2.95,-2.30)$ & $-2.85^{* * *}(-3.17,-2.52)$ \\
\hline$>10$ days & $-4.08^{* * *}(-4.69,-3.48)$ & $-4.68^{* * *}(-5.28,-4.07)$ \\
\hline \multicolumn{3}{|l|}{ Parental supervision } \\
\hline Rarely & $5.98^{* * *}(3.44,8.53)$ & $5.86^{* * *}(3.31,8.41)$ \\
\hline Sometimes & $1.25(-2.37,2.62)$ & $5.66(-1.93,3.06)$ \\
\hline Most of the time & $6.48^{* * *}(3.69,9.27)$ & $6.84^{* * *}(4.04,9.63)$ \\
\hline Always & $7.33(4.79,9.86)$ & $6.97^{* * *}(4.43,9.51)$ \\
\hline \multicolumn{3}{|c|}{ Parental connectedness } \\
\hline Rarely & $5.98^{* * *}(3.44,8.53)$ & $6.34^{* * *}(3.65,9.03)$ \\
\hline Sometimes & $1.25(-2.37,2.62)$ & $5.96(3.44,8.49)$ \\
\hline Most of the time & $6.48^{* * *}(3.69,9.27)$ & $1.92 * * *(1.63,2.20)$ \\
\hline Always & $7.33^{* * *}(4.79,9.86)$ & $3.559^{* * *}(3.32,3.86)$ \\
\hline \multicolumn{3}{|l|}{ Parental bonding } \\
\hline Rarely & $-9.73^{* * *}(-1.26,-6.88)$ & $-8.33^{* * *}(-1.12,-5.47)$ \\
\hline Sometimes & $-7.61^{* * *}(-1.03,-4.96)$ & $-6.24^{* * *}(-8.89,-3.59)$ \\
\hline Most of the time & $-1.99(-4.85,8.68)$ & $1.45(-2.72,3.01)$ \\
\hline Always & $1.30^{* * *}(1.03,1.57)$ & $1.48^{* * *}(1.21,1.75)$ \\
\hline Constant & $8.15^{* * *}$ & $7.96^{* * *}$ \\
\hline $\mathrm{R}^{2}$ & 0.17 & 0.17 \\
\hline $\mathrm{N}$ & 167,286 & 167,286 \\
\hline
\end{tabular}

\subsection{Effects of Bullying on Psychological Well-Being in Adolescents of Different Gender}

Table 5 demonstrates the effects of bullying frequency and bullying form on the mental health of adolescents by gender. Overall, both bullying frequency and bullying form had a significant negative effect on both male and female adolescents in the sample across continents $(p<0.001)$. In the total sample, the negative effect of bullying frequency on the mental health of female adolescents was more significant than that of males $(p<0.001)$. Specifically, the negative effect of bullying frequency on the mental health of female adolescents was greater than that of males in the sample countries of the Eastern Mediterranean region, the South East Asian region, and the Western Pacific region; the negative effect of bullying frequency on males was greater when the bullying frequency was less than 19 days in the sample countries of the American region $(p<0.001)$.

Looking at the different forms of bullying, verbal bullying and neglect had a greater negative effect on overall female adolescents than on males, while physical bullying had a greater negative effect on overall male adolescents, supporting partial of H2. Across continents, all three forms of bullying had a significant negative effect on the mental health of male adolescents in Africa compared with females $(p<0.001)$; in the Americas, physical bullying had a greater negative effect on the mental health of male adolescents than females $(p<0.001)$, neglect had a greater negative effect on the mental health of female adolescents than males, and verbal bullying did not differ between the two sexes; in the Eastern Mediterranean region, physical bullying and verbal bullying had a greater negative effect on females than males $(p<0.001)$, and neglect had a more severe negative effect on males; in South East Asia, both physical bullying and verbal bullying had a more severe negative effect on females $(p<0.001)$, and neglect had a more severe negative effect on 
males $(p<0.001)$; in the Western Pacific, physical bullying and neglect had a more severe negative effect on female mental health, and verbal bullying had a more severe negative effect on male mental health.

Table 4. Effects of bullying on psychological well-being in adolescents of different gender $(\mathrm{N}=167,286)$.

\begin{tabular}{|c|c|c|c|c|c|c|c|c|c|c|c|c|}
\hline & \multicolumn{2}{|c|}{ Total } & \multicolumn{2}{|c|}{ African } & \multicolumn{2}{|c|}{ Americas } & \multicolumn{2}{|c|}{$\begin{array}{c}\text { Eastern } \\
\text { Mediterranean }\end{array}$} & \multicolumn{2}{|c|}{ South East Asia } & \multicolumn{2}{|c|}{ Western Pacific } \\
\hline & Male & Female & Male & Female & Male & Female & Male & Female & Male & Female & Male & Female \\
\hline $\begin{array}{l}\text { Frequency } \\
\text { of being } \\
\text { bullied }\left(X^{2}\right)\end{array}$ & & $293.43 * * *$ & & 4.80 & & $26.69^{* * *}$ & & $284.47^{* * *}$ & & $168.79^{* * *}$ & & $67.34^{* * *}$ \\
\hline 1-5 days & -1.21 & -1.23 & -1.21 & $\begin{array}{r}-9.93 \\
* * *\end{array}$ & $\begin{array}{r}-1.29 \\
* * *\end{array}$ & -1.23 & -1.15 & -1.55 & -1.08 & -1.22 & -1.03 & $\begin{array}{r}-1.16 \\
* * *\end{array}$ \\
\hline 6-19 days & -1.40 & -1.45 & -1.16 & -1.29 & -1.51 & -1.48 & -1.50 & -1.83 & -1.02 & -1.69 & -1.25 & -1.16 \\
\hline$>20$ days & $\begin{array}{r}-7.01 \\
* * *\end{array}$ & $\begin{array}{r}-7.94 \\
* * *\end{array}$ & $-\underset{* * *}{6.74}$ & -7.10 & -7.54 & -8.25 & -6.15 & $\begin{array}{r}-8.46 \\
* * *\end{array}$ & $-\underset{* * *}{6.44}$ & -8.50 & $\begin{array}{r}-5.95 \\
* * *\end{array}$ & $\begin{array}{r}-7.36 \\
* * *\end{array}$ \\
\hline $\begin{array}{l}\text { Form of being } \\
\text { bullied }\left(X^{2}\right)\end{array}$ & & $1.0^{* * *}$ & & $73.69^{* * *}$ & & $424.39^{* * *}$ & & $547.14^{* * *}$ & & $211.67^{* * *}$ & & $224.02 * * *$ \\
\hline Physical & -7.86 & -6.62 & -7.21 & -7.02 & -8.64 & -5.63 & -8.10 & -9.72 & -6.93 & -8.36 & $-\underset{* * *}{5.94}$ & $-\begin{array}{r}-6.48 \\
* * *\end{array}$ \\
\hline Verbal & -9.55 & -1.01 & -9.37 & $\begin{array}{r}-9.17 \\
* * *\end{array}$ & -1.07 & -1.07 & -1.20 & -8.13 & -1.11 & -8.62 & $\begin{array}{r}-8.39 \\
* * *\end{array}$ & $\begin{array}{r}-8.05 \\
* * * *\end{array}$ \\
\hline Neglect & $\begin{array}{r}-1.24 \\
* * * * \\
\end{array}$ & -1.18 & -6.80 & -1.11 & -1.28 & $\begin{array}{r}-1.33 \\
* * * \\
\end{array}$ & $\begin{array}{r}-1.70 \\
* * *\end{array}$ & -1.40 & -1.30 & -1.14 & $\begin{array}{r}-1.25 \\
* * * \\
\end{array}$ & $\begin{array}{r}-9.89 \\
* * * \\
\end{array}$ \\
\hline
\end{tabular}

\subsection{Effects of Bullying on Psychological Well-Being in Adolescents of Different Ages}

Table ?? demonstrates the effects of bullying and different forms of bullying on the mental health of adolescents of different ages across continents and their variability. In terms of bullying frequency, bullying frequency had a greater negative effect on the overall mental health of adolescents under the age of 15 than adolescents over the age of 15 $(p<0.001)$. In terms of forms of bullying, physical bullying, verbal bullying and neglect had a greater negative effect on the mental health of adolescents under 15 years old than adolescents over 15 years old in the total sample $(p<0.001)$ as hypothesized. Among the regions, the negative effect of neglect on the mental health of adolescents over the age of 15 was more significant in the sample countries of the Western Pacific region $(p<0.001)$, and the negative effect of physical bullying and verbal bullying on the mental health of adolescents under the age of 15 was more significant $(p<0.001)$; the situation in the other regions was consistent with that of the overall sample.

Table 5. Effects of bullying on psychological well-being in adolescents of different gender $(\mathrm{N}=167,286)$.

\begin{tabular}{|c|c|c|c|c|c|c|c|c|c|c|c|c|}
\hline & \multicolumn{2}{|c|}{ Total } & \multicolumn{2}{|c|}{ African } & \multicolumn{2}{|c|}{ Americas } & \multicolumn{2}{|c|}{$\begin{array}{c}\text { Eastern } \\
\text { Mediterranean }\end{array}$} & \multicolumn{2}{|c|}{ South East Asia } & \multicolumn{2}{|c|}{ Western Pacific } \\
\hline & $\geq 15$ & $<15$ & $\geq 15$ & $<15$ & $\geq 15$ & $<15$ & $\geq 15$ & $<15$ & $\geq 15$ & $<15$ & $\geq 15$ & $<15$ \\
\hline $\begin{array}{l}\text { Frequency } \\
\text { of being } \\
\text { bullied }\left(X^{2}\right)\end{array}$ & & $218.44^{* * *}$ & & $10.73 *$ & & $8.11 *$ & & $35.85^{* * *}$ & & $19.10^{* * *}$ & & $815.58^{* * *}$ \\
\hline $1-5$ days & $-1.07^{* * *}$ & $-1.25^{* * *}$ & $-9.92 * * *$ & $-1.20^{* * *}$ & $-1.16^{* * *}$ & $-1.31^{* * *}$ & $-1.23^{* * *}$ & $-1.40^{* * *}$ & $-7.83^{* * *}$ & $-1.32 * * *$ & $-1.01^{* * *}$ & $-1.13^{* * *}$ \\
\hline 6-19 days & $-1.30 * * *$ & $-1.46^{* * *}$ & $-1.09^{* * *}$ & $-1.36^{* * *}$ & $-1.46^{* * *}$ & $-1.50 * * *$ & $-1.68^{* * *}$ & $-1.64^{* * *}$ & $-1.08^{* * *}$ & $-1.41^{* * *}$ & $-1.00 * * *$ & $-1.31 * * *$ \\
\hline$>20$ days & $-6.80 * * *$ & $-7.61^{* * *}$ & $-6.29 * * *$ & $-7.64 * * *$ & $-7.24 * * *$ & $-8.27^{* * *}$ & $-6.78 * * *$ & $-7.71^{* * *}$ & $-6.68^{* * *}$ & $-7.97^{* * *}$ & $-6.56^{* * *}$ & $-6.70 * * *$ \\
\hline $\begin{array}{l}\text { Form of being } \\
\text { bullied }\left(X^{2}\right)\end{array}$ & & $211.83^{* * *}$ & & $23.29 * * *$ & & $25.00^{* * *}$ & & $56.24^{* * *}$ & & $70.41^{* * *}$ & & $703.00 * * *$ \\
\hline Physical & $-5.97 * * *$ & $-6.72 * * *$ & $-7.14^{* * *}$ & $-7.20^{* * *}$ & $-6.21^{* * *}$ & $-7.82^{* * *}$ & $-8.80^{* * *}$ & $-8.86^{* * *}$ & $-5.56^{* * *}$ & $-7.60 * * *$ & $-5.65^{* * *}$ & $-6.23 * * *$ \\
\hline Verbal & $-9.10^{* * *}$ & $-1.02 * * *$ & $-8.18^{* * *}$ & $-9.32 * * *$ & $-1.02 * * *$ & $-1.08^{* * *}$ & $-9.49^{* * *}$ & $-9.98^{* * *}$ & $-9.71 * * *$ & $-9.97 * * *$ & $-7.71^{* * *}$ & $-8.26^{* * *}$ \\
\hline Neglect & $-1.09 * * *$ & $-1.32 * * *$ & $-8.04^{* * *}$ & $-8.65^{* * *}$ & $-1.19 * * *$ & $-1.31^{* * *}$ & $-1.40^{* * *}$ & $-1.56^{* * *}$ & $-1.18^{* * *}$ & $-1.25 * * *$ & $-9.75^{* * *}$ & $-1.15^{* * *}$ \\
\hline
\end{tabular}

\subsection{The Protective Effect of Parental Support on the Psychological Well-Being}

To test the potential moderating role of parental support as a protective factor on adolescent mental health after bullying, the study conducted the procedure to test significant 
interactions. The results from Table 6 show that being bullied was negatively associated with mental health in three models $(p<0.001)$. Significant interaction effects between parental supervision and being bullied $(p<0.001)$, between parental connectedness and being bullied $(p<0.001)$, between parental bonding and being bullied $(p<0.001)$ were found to be positively associated with psychological well-being, indicating that the moderating effect of parental support occurred in the protection of mental health of adolescents who experienced being bullied as H3 hypothesized.

Table 7 shows the results of the effect of parental support on the mental health of adolescents following different forms of bullying. Among them, "parental connectedness" had a positive protective effect on the mental health of adolescents after verbal bullying or peer neglect, i.e., the more parents understand the adolescents' distress after verbal bullying or neglect at school, the higher the level of mental health of the adolescents, and the frequency of parental understanding increases by one unit, the level of mental health increased by 8.71 units $(p<0.001)$ and 1.05 units $(p<0.001)$, respectively; "parental bonding" had a positive restorative effect on the psychological health of adolescents who were verbally bullied, i.e., for each unit increase in the frequency of "parental bonding", the psychological health level of adolescents who were verbally bullied increased by 2.47 units $(p<0.05)$.

Table 6. Tested moderation models with psychological well-being as outcomes predicted by being bullied, parental support and multiplicative interaction terms $(\mathrm{N}=167,286)$.

\begin{tabular}{lrrr}
\hline & B & $\mathbf{R}^{\mathbf{2}}$ & \multicolumn{1}{c}{$\mathbf{9 5 \%} \mathbf{C I}$} \\
\hline Model 1 & 0.15 & $(-9.60,-1.03)$ \\
Being bullied & $-9.98^{* * *}$ & & $(2.13,4.31)$ \\
Parental supervision * Being bullied & $3.22^{* * *}$ & & $(8.29,8.54)$ \\
Constant & $8.41^{* * *}$ & & \\
\hline Model 2 & & 0.16 & $(-1.18,-1.10)$ \\
Being bullied & $-1.14^{* * *}$ & & $(7.05,9.34)$ \\
Parental connectedness * Being bullied & $8.19^{* * *}$ & & $(8.30,8.55)$ \\
Constant & $8.43^{* * *}$ & & $(-1.09,-1.01)$ \\
\hline Model 3 & & 0.15 & $(3.78,6.07)$ \\
Being bullied & $-1.05^{* * *}$ & & $(8.30,8.55)$ \\
Parental bonding * Being bullied & $4.93^{* * *}$ & & \\
Constant & $8.43^{* * *}$ & &
\end{tabular}

Table 7. Association of protective effect of parental support with psychological well-being by forms of being bullied $(\mathrm{N}=167,286)$.

\begin{tabular}{|c|c|c|c|}
\hline & Physical & Verbal & Neglect \\
\hline Parental supervision & -1.53 & 8.21 & 3.14 \\
\hline $\begin{array}{l}\text { Parental } \\
\text { connectedness }\end{array}$ & 2.36 & $8.71^{* * *}$ & $1.05^{* * *}$ \\
\hline Parental bonding & 2.23 & 2.47 * & 8.98 \\
\hline Constant & $0.00^{* * *}$ & $0.00^{* * *}$ & $0.00 * *$ \\
\hline $\mathrm{N}$ & 7554 & 20,875 & 3031 \\
\hline $\mathrm{R}^{2}$ & 0.08 & 0.10 & 0.08 \\
\hline
\end{tabular}

\section{Discussion}

The study examined the overall prevalence of bullying among adolescents and the prevalence of different forms of bullying in a total of 167,286 sample in five regions, and further analyzed the effect of different forms of bullying on adolescent mental health, the protective role of parental support, and the main findings were as follows:

Firstly, adolescent bullying cannot be ignored, with the highest prevalence of verbal bullying. Our study showed that the overall prevalence of bullying among adoles- 
cents in the 167,286 sample countries was $32.03 \%$, a result that was consistent with the previous UNICEF report published in 2018 that more than one-third of students aged 13-15 worldwide experienced bullying. The results of Biswas et al. (2020) and Elgar et al. (2015) cross-regional comparative studies on bullying and violence among adolescents were generally consistent with the results of the two studies on the prevalence of bullying among adolescents, which were 31\% [32] and 30\% [8], respectively. From the results of the cross-regional comparison, the highest prevalence of bullying among adolescents (47.36\%) was found in the sample countries in the African region, which may be related to the low-income level, poorer schools, and social environment, war, and riots in the African region [46]. In terms of the prevalence of different forms of bullying, verbal bullying had the highest prevalence $(66.36 \%)$, followed by physical bullying $(24.02 \%)$, and neglect had the lowest prevalence $(9.62 \%)$. The results of a survey conducted by Scheithauer et al. (2006) in Germany with students in grades 5-10 [47], and the results of the prevalence of six forms of bullying among 2667 Italian secondary school students, obtained by Vieno et al. in 2011 using the results of the Health Behavior in School-aged Children Survey database, also both showed the highest prevalence of verbal bullying, consistent with the findings of this paper [48]. This suggested that verbal bullying, which takes the form of making fun of a peer's race, nationality, color, creed, body, and appearance, was the most prevalent and most likely to occur among adolescents because it was the most recognizable and less costly to occur. However, it was worth pointing out that the findings for the prevalence of physical bullying and neglect in this study differ slightly from those of the two studies mentioned above, due to the different criteria used to measure them.

Secondly, compared with physical bullying and neglect, verbal bullying had the most serious negative effect on adolescent mental health. Not only did verbal bullying had the highest prevalence of the three forms of bullying, but it also had the most serious negative effect on adolescent mental health for two main reasons: firstly, verbal bullying occurred most frequently, and according to the study, the frequency of bullying significantly and negatively affects adolescent mental health, so the lower the level of mental health when adolescents suffered frequent ridicule or name-calling from peers; secondly, from the perspective of social identity theory, this highly discriminatory ridicule led to negative mental health outcomes, especially for adolescents with extremely strong identity, and this discrimination increased their psychological distress [49].

Thirdly, overall, the frequency of bullying had a greater negative effect on the mental health of female adolescents compared with male adolescents, which was consistent with the findings of a recent study conducted in the United States that school bullying had a greater effect on psychological depression in females than in males [26]. In addition, physical bullying had a greater negative effect on the mental health of male adolescents, and verbal bullying and neglect had a greater negative effect on the mental health of female adolescents. This was generally consistent with previous research finding that depressive symptoms were more pronounced after active forms of bullying (i.e., physical bullying) in boys and after passive forms of bullying (i.e., verbal and relational bullying) in girls [28,50]. This would require further exploration of the effect of different forms of bullying on the mental health of male and female adolescents in specific regions. While we need to protect boys and girls equally from bullying, countries also need to consider the gender differences in the occurrence and effect of different forms of bullying in their countries and pay targeted attention to adolescents who are victims of bullying.

Fourth, the frequency of bullying had a more significant negative effect on the mental health of adolescents under the age of 15, and different forms of bullying also had a more significant negative effect on the mental health of adolescents under the age of 15 . Previous studies have found that the odds of bullying are higher for younger adolescents (under 15) $[25,51]$. Compared with younger adolescents, older adolescents (15 years and older) were more aware of self-concept and self-regulation in terms of self-perception and psychological construction [49], so both the frequency of bullying and the different forms of bullying had a more significant negative effect on the mental health of adolescents 
under the age of 15. In addition, the study showed regional differences in mental health of adolescents in different age groups after various forms of bullying, which provided a basis for the development and implementation of intervention policies in each region or country.

Finally, in terms of protective factors, "parental supervision", "parental connectedness" and "parental bonding" played positive roles in the relationship between bullying and adolescent mental health. Positive relationships, especially positive family relationships that provided intimacy, support, trust, emotional comfort, and a sense of belonging, are one of the key elements of resiliency [52]. In such a family environment, even if adolescents were abused and bullied, they could still buffer the stress and shock from other aspects by increasing their self-efficacy, self-worth, and emotional belongingness [53]. "Parental connectedness" and "parental bonding" were important indicators of parent-child intimacy and emotional comfort, and played a positive role in adolescents' resilience. However, there were no consistent conclusions to the role of "parental supervision". Some studies have not found a significant link between parental supervision and mental health after bullying $[54,55]$. Others have identified the lack of parental supervision as a risk factor to adolescents' mental health development [56], which is consistent with the current study. Future research would explore how the degree or the forms of parental supervision influence mental health when adolescents experience bullying.

Limited by the consistency of the GSHS database, this study suffered from the following shortcomings: Firstly, the countries or regions selected represent only some of the five regions. We did not contain the European continent because only one country provided useful data. Future studies would include more specific countries to explore the global adolescent bullying situation. Secondly, the GSHS used a self-administered questionnaire, and although self-administration was an acceptable way to collect data on adolescent bullying victimization, there was a limitation of possible shared method variance. Finally, we observed significant regional differences in the prevalence of different forms of bullying, including gender differences and age differences, and future research would consider social context and cultural heterogeneity to explain regional differences better and provide more possibilities for countries to implement adolescent bullying intervention programs.

\section{Conclusions}

Despite these limitations, our study contributed to the exploration of adolescent bullying in the following ways: firstly, unlike previous studies limited to individual countries or regions, our analysis covered 65 sample countries across five continents, providing more evidence for cross-regional comparative studies of adolescent bullying; secondly, in addition to focusing on bullying among adolescents as a whole and its effect on mental health, we focused on intergroup differences in adolescent subgroups (gender groups and age groups) to provide a basis for targeted development of specific intervention policies for different groups of adolescents. Finally, we focused on the potential protective factors of adolescent bullying and found that "parental supervision", "parental connectedness" and "parental bonding" played a positive role in protecting the psychological health of adolescents who were bullied. The above findings suggested that, as a global public health problem, adolescent bullying should attract sufficient policy concern and practical intervention, and further establish a comprehensive adolescent social protection mechanism and protection system including family, school, and community.

Author Contributions: Conceptualization, X.M.; methodology, X.M. and J.L.; software, Z.X. and J.L.; validation, X.M., J.L. and Z.X.; formal analysis, X.M., J.L. and Z.X.; data curation, Z.X.; writing-original draft preparation, X.M. and J.L.; writing-review and editing, X.M., J.L. and Z.X.; visualization, X.M., J.L. and Z.X.; supervision, X.M.; project administration, X.M. All authors have read and agreed to the published version of the manuscript.

Funding: This research was funded by Social Science Planning Fund of Liaoning Province (Grant Number: L20BGL004) and the Fundamental Research Funds for the Central Universities supported by Ministry of Education of China (Grant Number: N2114001). 
Institutional Review Board Statement: Not applicable.

Informed Consent Statement: Not applicable.

Data Availability Statement: The data are available online at https://www.cdc.gov/gshs / (accessed on 10 December 2021).

Acknowledgments: The authors would like to thank children and their families who participated in the GSHS. The authors would like to thank World Health Organization for providing the datasets and codebook for data analysis of GSHS.

Conflicts of Interest: The authors declare no conflict of interest.

\section{References}

1. Klomek, A.B.; Sourander, A.; Elonheimo, H. Bullying by peers in childhood and effects on psychopathology, suicidality, and criminality in adulthood. Lancet Psychiatry 2015, 2, 930-941. [CrossRef]

2. Thomas, H.J.; Connor, J.P.; Scott, J.G. Integrating Traditional Bullying and Cyberbullying: Challenges of Definition and Measurement in Adolescents-A Review. Educ. Psychol. Rev. 2014, 27, 135-152. [CrossRef]

3. Zhong, M.T.; Huang, X.C.; Huebner, E.S.; Tian, L.L. Association between bullying victimization and depressive symptoms in children: The mediating role of self-esteem. J. Affect. Disord. 2021, 294, 322-328. [CrossRef] [PubMed]

4. Thomas, H.J.; Chan, G.C.; Scott, J.G.; Connor, J.P.; Kelly, A.B.; Williams, J. Association of different forms of bullying victimisation with adolescents' psychological distress and reduced emotional wellbeing. Aust. N. Z. J. Psychiatry 2016, 50, 371-379. [CrossRef]

5. Fund, U.N.I.C.E. Half of World's Teens Experience Peer Violence in and around School. Available online: https://www.unicef. org/press-releases/half-worlds-teens-experience-peer-violence-and-around-school-unicef (accessed on 10 December 2021).

6. World Health Organization. Children: New Threats to Health. Available online: https://www.who.int/news-room/fact-sheets / detail/children-new-threats-to-health (accessed on 10 December 2021).

7. World Health Organization. Youth Violence. Available online: https://www.who.int/news-room/fact-sheets/detail/youthviolence (accessed on 10 December 2021).

8. Elgar, F.J.; McKinnon, B.; Walsh, S.D.; Freeman, J.; Donnelly, P.D.; de Matos, M.G.; Gariepy, G.; Aleman-Diaz, A.Y.; Pickett, W.; Molcho, M.; et al. Structural Determinants of Youth Bullying and Fighting in 79 Countries. J. Adolesc. Health 2015, 57, 643-650. [CrossRef]

9. Yen, C.F.; Huang, M.F.; Kim, Y.S.; Wang, P.W.; Tang, T.C.; Yeh, Y.C.; Lin, H.C.; Liu, T.L.; Wu, Y.Y.; Yang, P. Association between types of involvement in school bullying and different dimensions of anxiety symptoms and the moderating effects of age and gender in Taiwanese adolescents. Child Abus. Negl. 2013, 37, 263-272. [CrossRef]

10. Liu, T.L.; Hsiao, R.C.; Chou, W.J.; Yen, C.F. Self-Reported Depressive Symptoms and Suicidality in Adolescents with AttentionDeficit/Hyperactivity Disorder: Roles of Bullying Involvement, Frustration Intolerance, and Hostility. Int. J. Environ. Res. Public Health 2021, 18, 7829. [CrossRef]

11. Li, L.; Chen, X.; Li, H. Bullying victimization, school belonging, academic engagement and achievement in adolescents in rural China: A serial mediation model. Child. Youth Serv. Rev. 2020, 113, 104946. [CrossRef]

12. Gentry, R.H.; Pickel, K.L. Male and Female Observers' Evaluations of a Bullying Case as a Function of Degree of Harm, Type of Bullying, and Academic Level. J. Aggress. Maltreatment Trauma 2014, 23, 1038-1056. [CrossRef]

13. Smith, A.U.; Reidy, D. Bullying and suicide risk among sexual minority youth in the United States. Prev. Med. 2021, 153, 106728. [CrossRef]

14. Tang, J.J.; Yu, Y.; Wilcox, H.C.; Kang, C.; Wang, K.; Wang, C.; Wu, Y.; Chen, R. Global risks of suicidal behaviours and being bullied and their association in adolescents: School-based health survey in 83 countries. EClinicalMedicine 2020, 19, 100253. [CrossRef]

15. Zhu, X.X.; Griffiths, H.; Eisner, M.; Hepp, U.; Ribeaud, D.; Murray, A.L. Developmental associations between bullying victimization and suicidal ideation and direct self-injurious behavior in adolescence and emerging adulthood. J. Child Psychol. Psyc. 2021, 9, 1-9. [CrossRef]

16. González-Cabrera, J.; Montiel, I.; Ortega-Barón, J.; Calvete, E.; Orue, I.; Machimbarrena, J.M. Epidemiology of Peer Victimization and its Impact on Health-Related Quality of Life in Adolescents: A Longitudinal Study. Sch. Ment. Health 2021, 13, 338-346. [CrossRef]

17. Staubli, S.; Killias, M. Long-term outcomes of passive bullying during childhood: Suicide attempts, victimization and offending. Eur. J. Criminol. 2011, 8, 377-385. [CrossRef]

18. Bettencourt, A.; Farrell, A.; Liu, W.; Sullivan, T. Stability and change in patterns of peer victimization and aggression during adolescence. J. Clin. Child Adolesc. Psychol. 2013, 42, 429-441. [CrossRef]

19. Choi, B.; Park, S. Who Becomes a Bullying Perpetrator After the Experience of Bullying Victimization? The Moderating Role of Self-esteem. J. Youth Adolesc. 2018, 47, 2414-2423. [CrossRef]

20. Yoon, D.; Shipe, S.L.; Park, J.; Yoon, M. Bullying patterns and their associations with child maltreatment and adolescent psychosocial problems. Child Youth Serv. Rev. 2021, 129, 106178. [CrossRef]

21. Maunder, R.E.; Harrop, A.; Tattersall, A.J. Pupil and staff perceptions of bullying in secondary schools: Comparing behavioural definitions and their perceived seriousness. Educ. Res. 2010, 52, 263-282. [CrossRef] 
22. Chen, L.M.; Liu, K.S.; Cheng, Y.Y. Validation of the perceived school bullying severity scale. Educ. Psychol. 2012, 32, 169-182. [CrossRef]

23. Baier, D.; Hong, J.S.; Kliem, S.; Bergmann, M.C. Consequences of Bullying on Adolescents' Mental Health in Germany: Comparing Face-to-Face Bullying and Cyberbullying. J. Child Fam. Stud. 2018, 28, 2347-2357. [CrossRef]

24. Turner, M.G.; Exum, M.L.; Brame, R.; Holt, T.J. Bullying victimization and adolescent mental health: General and typological effects across sex. J. Crim. Justice 2013, 41, 53-59. [CrossRef]

25. Shongwe, M.C.; Dlamini, L.P.; Simelane, M.S.; Masuku, S.K.S.; Shabalala, F.S. Are there Gender Differences in the Prevalence and Correlates of Bullying Victimization Among in-School Youth in Eswatini? Sch. Ment. Health 2021, 13, 299-311. [CrossRef]

26. Kim, Y.K.; Kim, Y.J.; Maleku, A.; Moon, S.S. Typologies of Peer Victimization, Depression, and Alcohol Use among High School Youth in the United States: Measuring Gender Differences. Soc. Work Public Health 2019, 34, 293-306. [CrossRef] [PubMed]

27. Wang, J.; Iannotti, R.J.; Nansel, T.R. School bullying among adolescents in the United States: Physical, verbal, relational, and cyber. J. Adolesc. Health 2009, 45, 368-375. [CrossRef]

28. Yen, C.F.; Yang, P.; Wang, P.W.; Lin, H.C.; Liu, T.L.; Wu, Y.Y.; Tang, T.C. Association between school bullying levels/types and mental health problems among Taiwanese adolescents. Compr. Psychiatry 2014, 55, 405-413. [CrossRef]

29. Wilkins, N.; Myers, L.; Kuehl, T.; Bauman, A.; Hertz, M. Connecting the Dots: State Health Department Approaches to Addressing Shared Risk and Protective Factors Across Multiple Forms of Violence. J. Public Health Manag. Pract. 2018, 24 (Suppl. 1), S32-S41. [CrossRef]

30. Yule, K.; Houston, J.; Grych, J. Resilience in Children Exposed to Violence: A Meta-analysis of Protective Factors Across Ecological Contexts. Clin. Child Fam. Psychol. Rev. 2019, 22, 406-431. [CrossRef]

31. Zych, I.; Farrington, D.P.; Ttofi, M.M. Protective factors against bullying and cyberbullying: A systematic review of meta-analyses. Aggress. Violent Behav. 2019, 45, 4-19. [CrossRef]

32. Biswas, T.; Scott, J.G.; Munir, K.; Thomas, H.J.; Huda, M.M.; Hasan, M.M.; David de Vries, T.; Baxter, J.; Mamun, A.A. Global variation in the prevalence of bullying victimisation amongst adolescents: Role of peer and parental supports. EClinicalMedicine 2020, 20, 100276. [CrossRef]

33. Sonja, P.; Julian, D.; Therese, S.; Donna, C. Bullying in school and cyberspace: Associations with depressive symptoms in Swiss and Australian adolescents. Child Adolesc. Psychiatry Ment. Health 2010, 4, 28.

34. Srabstein, J.C. The Global Implications of Bullying and Other Forms of Maltreatment, in the Context of Migratory Trends and Psychiatric Resources. Child Adolesc. Psychiatry. Clin. N. Am. 2015, 24, 799-810. [CrossRef]

35. Baldry, A.C.; Farrington, D.P. Protective Factors as Moderators of Risk Factors in Adolescence Bullying. Soc. Psychol. Educ. 2005, 8, 263-284. [CrossRef]

36. Meinck, F.; Cluver, L.D.; Boyes, M.E.; Ndhlovu, L.D. Risk and Protective Factors for Physical and Emotional Abuse Victimisation amongst Vulnerable Children in South Africa. Child Abus. Rev. 2015, 24, 182-197. [CrossRef]

37. Dendup, T.; Putra, I.G.N.E.; Dorji, T.; Tobgay, T.; Dorji, G.; Phuntsho, S.; Tshering, P. Correlates of sedentary behaviour among Bhutanese adolescents: Findings from the 2016 Global School-based health survey. Child. Youth Serv. Rev. 2020, 119, 105520. [CrossRef]

38. Li, W.; Zhao, Y.; Wang, Q.; Zhou, J. Twenty Years of Entropy Research: A Bibliometric Overview. Entropy 2019, 21, 694. [CrossRef]

39. Huang, Z.G.; Li, J. Influence of land acquisition for rural tourism on the well- being of landless farmers based on the empirical analysis of PSM model. Resour. Sci. 2021, 43, 171-184. [CrossRef]

40. Smith, P.K.; López-Castro, L.; Robinson, S.; Görzig, A. Consistency of gender differences in bullying in cross-cultural surveys. Aggress. Violent Behav. 2019, 45, 33-40. [CrossRef]

41. Chen, L.; Lu, R.R.; Duan, J.L.; Ma, J.; Zhu, G.R.; Song, Y.; Lau, P.W.C.; Prochaska, J.J. Combined Associations of Smoking and Bullying Victimization With Binge Drinking Among Adolescents in Beijing, China. Front. Psychiatry 2021, 12, 1-13. [CrossRef] [PubMed]

42. Hammar, E.; Bladh, M.; Agnafors, S. Mental health and experience of being bullied in 12-year-old children with overweight and obesity. Acta Paediatr. 2020, 109, 1450-1457. [CrossRef]

43. Malecki, C.K.; Demaray, M.K.; Smith, T.J.; Emmons, J. Disability, poverty, and other risk factors associated with involvement in bullying behaviors. J. Sch. Psychol. 2020, 78, 115-132. [CrossRef]

44. Petrella, E.; Grandi, G.; Di Cerbo, L.; Bertarini, V.; Neri, I.; Facchinetti, F. 813: Changes of body composition in women with $\mathrm{BMI} \geq 25$ included in a lifestyle program. Correlation with birthweight's centile. Am. J. Obstet. Gynecol. 2018, 218, S484-S485. [CrossRef]

45. Burns, R.D.; Bai, Y.; Pfledderer, C.D.; Brusseau, T.A.; Byun, W. Movement Behaviors and Perceived Loneliness and Sadness within Alaskan Adolescents. Int. J. Environ. Res. Public Health 2020, 17, 6866. [CrossRef] [PubMed]

46. Juan, A.; Zuze, L.; Hannan, S.; Govender, A.; Reddy, V. Bullies, victims and bully-victims in South African schools: Examining the risk factors. S. Afr. J. Educ. 2018, 38, S1-S10. [CrossRef]

47. Scheithauer, H.; Hayer, T.; Petermann, F.; Jugert, G. Physical, verbal, and relational forms of bullying among German students: Age trends, gender differences, and correlates. Aggress. Behav. 2006, 32, 261-275. [CrossRef]

48. Vieno, A.; Gini, G.; Santinello, M. Different forms of bullying and their association to smoking and drinking behavior in Italian adolescents. J. Sch. Health 2011, 81, 393-399. [CrossRef]

49. Ybrandt, H. The relation between self-concept and social functioning in adolescence. J. Adolesc. 2008, 31, 1-16. [CrossRef] 
50. Smith, P.K.; Sharp, S. The Problem of School Bullying; Routledge: London, UK, 1994.

51. Peltzer, K.; Pengpid, S. Prevalence of bullying victimisation and associated factors among in-school adolescents in Mozambique. J. Psychol. Afr. 2020, 30, 64-68. [CrossRef]

52. Giumetti, G.W.; Kowalski, R.M.; Feinn, R.S. Predictors and outcomes of cyberbullying among college students: A two wave study. Aggress. Behav. 2021, 48, 40-54. [CrossRef]

53. Gloppen, K.; McMorris, B.; Gower, A.; Eisenberg, M. Associations between bullying involvement, protective factors, and mental health among American Indian youth. Am. J. Orthopsychiatry 2018, 88, 413-421. [CrossRef]

54. Gómez-Ortiz, O.; Del Rey, R.; Casas, J.-A.; Ortega-Ruiz, R. Parenting styles and bullying involvement/Estilos parentales e implicación en bullying. Cult. Y Educ. 2014, 26, 132-158. [CrossRef]

55. Gomez-Ortiz, O.; Romera, E.M.; Ortega-Ruiz, R. Parenting styles and bullying. The mediating role of parental psychological aggression and physical punishment. Child Abus. Negl. 2016, 51, 132-143. [CrossRef]

56. Espelage, D.L.; Bosworth, K.; Simon, T.R. Examining the social context of bullying behaviors in early adolescence. J. Couns. Dev. 2000, 73, 326-333. [CrossRef] 